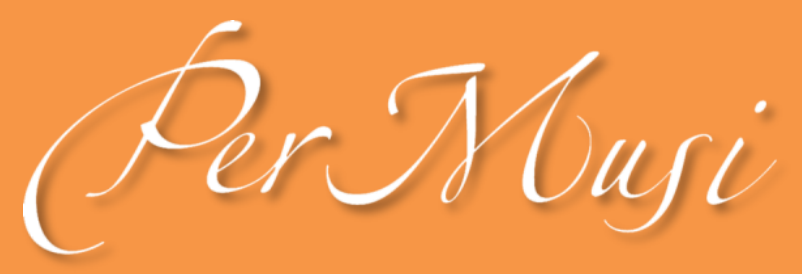

eISSN 2317-6377

\title{
Música eletroacústica audiovisual para VR
}

\author{
Fabio Wanderley Janhan Sousa \\ https://orcid.org/0000-0002-0844-8841 \\ Federal University of Minas Gerais, School of Music \\ fabiojanhan@gmail.com
}

SCIENTIFIC ARTICLE

Submitted date: 12 Apr 2020

Final approval date: 22 Jul 2021

Resumo: O presente artigo tem como objetivo definir o desenvolvimento da música eletroacústica audiovisual para realidade virtual (VR) como uma manifestação artística emergente. Revisitando conceitos e terminologias de diversos autores (Gibbs, 2007; Leite, 2004; Lima, 2011; Fry, 1920) com relação às mais diversas manifestações audiovisuais, consolidamos a definição de Hill (2010) e a expandimos para um sistema de reprodução específico, o VR, como a mais apropriada para o nosso objeto de estudos. A manutenção do que denominamos de espaço extrínseco (Henriksen, 2002) nesse tipo de manifestação possibilita a consolidação do mesmo como parâmetro musical. Primeiros estudos em música eletroacústica audiovisual para VR são apresentados como resultado de um trabalho de doutorado.

Palavras-chave: Música eletroacústica audiovisual; Realidade virtual na arte; Composição musical.

\section{TITLE: AUDIOVISUAL ELECTROACOUSTIC MUSIC FOR VR}

Abstract: This article aims to define the development of audiovisual electroacoustic music for virtual reality (VR) as an emerging artistic expression. Revisiting concepts and terminologies by several authors (Gibbs, 2007; Leite, 2004; Lima, 2011; Fry, 1920) in relation to the most diverse audiovisual manifestations, we consolidated Hill's definition (2010) and expanded it to a specific reproduction system, VR, as the most appropriate for our object of study. The maintenance of what we call extrinsic space (Henriksen, 2002) in this type of manifestation makes it possible to consolidate it as a musical parameter. First studies in audiovisual electroacoustic music for $V R$ are presented as result of doctoral work.

Keywords: Audiovisual electroacoustic music; Virtual reality in art; Musical composition. 


\section{Música Eletroacústica Audiovisual para VR}

Fabio Wanderley Janhan Sousa, Federal University of Minas Gerais, fabiojanhan@gmail.com

\section{Introdução}

Como ressaltado por Bethônico (2001), o uso simultâneo da imagem e do som tem pautado os meios de comunicação contemporâneos. Esse uso simultâneo de signos sonoros e visuais tem sido a principal ferramenta expressiva de manifestações artísticas e populares, principalmente pela sua aceitação social decorrente de sua força, à qual somos extremamente sensíveis. A riqueza, diversidade e profundidade do audiovisual em seus vários modos de presença e operações constitutivas o faz um significativo representante da multiplicidade do mundo da arte, sendo então uma síntese da sociedade atual, não somente como técnica objetiva, mas também como representação, fluxo e imaginário. "O AV tornou-se a forma mais adequada à expressão e ao conhecer da pluralidade humana de nossa sociedade; cada uma de suas manifestações tem seu modo diverso - com uma perspectiva própria - de contar a história do homem no século XX" (Bethônico 2001, 20).

O novo milênio, principalmente essa segunda década, se iniciou com uma explosão de material audiovisual distribuído pela internet. Além da possibilidade de se transmitir ao vivo não somente áudio, mas também vídeo, observamos o fato de a manipulação dos mesmos ter se tornado mais simples e acessível a usuários com pouca experiência, prometendo resultados impressionantes. Com isso, diversas portas se abriram, entre elas, a da distribuição de música com imagem em movimento pelos profissionais da área de entretenimento e comunicação. Não falamos aqui somente de videoclipes, palestras e vídeo-aulas, mas também de obras eletroacústicas com material visual, antes acessíveis somente em concertos especializados. O surgimento de novos gêneros musicais / audiovisuais se intensificou e o que denominamos aqui de música eletroacústica audiovisual ${ }^{1}$ encontrou seus meios de atingir o grande público.

$\mathrm{Na}$ transformação de processos técnicos em artísticos, a gravação e manipulação do áudio se desenvolveu na composição eletroacústica e a gravação e manipulação de vídeo na música visual (ou Visual Music): “A música visual pode ser definida como imagens visuais baseadas no tempo que estabelecem uma arquitetura temporal de maneira semelhante à música absoluta" (Evans 2005, 11)². É nessa trajetória de desenvolvimento de procedimentos técnicos em recursos estéticos, que se encontram as mídias audiovisuais

${ }^{1}$ Conceito definido por Andrew Hill para descrever "obras de música eletroacústica audiovisual que exploram as possibilidades que a combinação de suas duas mídias baseadas em tempo (som e imagem em movimento) permitem." (Hill 2010, 37). Original: "Electroacoustic audio-visual music works explore the possibilities that the combination of their two time-based media (sound and moving image) allow".

${ }^{2}$ Original: "Visual Music can be defined as time-based visual imagery that establishes a temporal architecture in a way similar to absolute music." 
adaptativas para a realidade virtual ${ }^{3}$, mídia emergente desde o ano de 2016. Refletir sobre as manifestações artísticas possíveis com esse novo formato de mídia, no presente trabalho, direcionado para o desenvolvimento da música eletroacústica audiovisual, exige um estudo histórico, mesmo que breve, com o intuito de constituir um panorama que contextualize as manifestações precursoras, através de uma pesquisa bibliográfica preliminar como a que se segue.

\section{Classificação das manifestações artísticas audiovisuais}

Bethônico adota o conceito de audiovisual como sendo uma "mensagem constituída da combinação de som e imagem" (Ferreira 1986, 199 apud Bethônico 1995, 105) e discute diferentes usos do termo com suas conotações negativas e positivas. Independente de se apresentar de forma durável ou efêmera, folclórica ou infográfica, dominante ou dominada, explorando próteses tecnológicas ou não, o audiovisual (termo adotado com essa grafia específica) pressupõe um termo descritivo originado de uma montagem que se apresente como maior do que suas partes constitutivas. Essa possibilidade de duas coisas que se somam, se tornarem algo maior do que a soma das partes, é desenvolvida também em estudos relacionados a hibridização e interatividade, como em Kwastek (2013, viii), que afirma que "a característica essencial da hibridização das artes é que a forma híbrida não pode ser dividida em seus componentes individuais: o todo é mais do que a soma de suas partes" ${ }^{4}$.

Voltando historicamente no desenvolvimento desses estudos sonoros e imagéticos, vemos o embrião da parte sonora do audiovisual no desenvolvimento do fonógrafo de Thomas Edison em 1877, passando pelo desenvolvimento do transmissor do rádio (1896) e do manifesto de música futurista de Russolo (L'Arte dei Rumori ${ }^{5}$ - 1913). Obras como Étude aux chemins de fer de Pierre Schaeffer e Poéme Eletronique de Edgar Varèse, se apresentam como o que seria chamado por Trevor Whishart em 1996 de arte sonora, uma forma distinta de música que explora as ideias apresentadas por John Cage de que o som por si mesmo poderia ser capaz de comunicar: "(...) Cage efetivamente criou a ideia de que o som em si mesmo poderia comunicar e, talvez o mais importante (para nós pelo menos), que ele poderia ser a base para uma forma de arte distinta" (Gibbs 2007, 34) ${ }^{6}$.

O termo "arte" sempre foi historicamente utilizado para designar trabalhos relacionados a pinturas ou até mesmo a esculturas (Gibbs 2007, 43). Em meados do século XX, quando a tecnologia possibilitou que o som fosse gravado e transformado em um objeto (pedaço de fita ou um sulco em um disco de vinil), passível de manipulações - sejam elas tão simples como o cortar e colar de pedaços de fitas magnéticas ou complexas como uma granulação ou reverberação - sendo modelado, esculpido e moldado, de acordo com estéticas

${ }^{3}$ Chamamos de mídia audiovisual adaptativa para realidade virtual aquele material audiovisual que se adapta ao direcionamento do olhar do espectador, transformando tanto o campo sonoro quanto o visual a partir da movimentação da cabeça do mesmo, possível através do $V R$ (realidade virtual), impulsionado pela indústria dos jogos digitais e desenvolvimento de smartphones com giroscópios e acelerômetros embutidos. ${ }^{4}$ Original: "The essential characteristic of the hybridization of the arts is that the hybrid form cannot be broken down into its individual components: the whole is more than the sum of its parts."

${ }^{5}$ Trad.: A arte dos ruídos

${ }^{6}$ Original: "(...) Cage effectively created the idea that sound by itself could communicate and, perhaps more importantly (for us at least), that it could be the basis for a distinct art form". 
artísticas emergentes, o antigo conceito de música se expandiu, se aproximando do que viria a ser denominado de "arte sonora"7.

No que diz respeito à adoção desse termo em específico, arte sonora, observamos claramente na literatura algumas discordâncias conceituais entre autores, principalmente se o expandirmos para o contexto atual. Nas palavras de Bernd Schulz $(1999,25)$, o "inexato termo de arte sonora", é "uma forma híbrida que se desenvolveu nas fronteiras entre música e artes visuais". Observamos na literatura também, uma descrição de Emmerson com uma visão um pouco mais ampla quando ele afirma: "acredito que a música seja um subconjunto da 'arte sonora' e que a 'arte sonora' seja um subconjunto da 'paisagem sonora' e que a 'paisagem sonora' seja realmente o mundo ao nosso redor, virtualmente completo" ${ }^{8}$ (Emmerson, apud Gibbs 2007, 65).

Fica claro através dessas citações que, enquanto Schulz coloca a arte sonora na fronteira entre a música e as artes visuais, Emmerson a vê como algo que engloba a música. Para Emmerson a música estaria então entre as diversas manifestações artísticas sonoras humanas, dessa forma, esculturas que produzem sons (denominadas também de esculturas sonoras) ${ }^{9}$ estariam lado a lado com a música pop, a eletroacústica, a música instrumental e a denominada paisagem sonora do compositor canadense Murray Schafer. Arte sonora seria então o nome dado ao que engloba tudo isso. A definição apresentada por Schultz, portanto, nos é favorita principalmente por ser mais utilizada no meio artístico e ser mais condizente com as produções contemporâneas que se auto denominam artes sonoras, se situando entre a música e as artes visuais.

Para além da tradicional composição instrumental, e para além do processo de produção fonográfica, os processos de manipulação sonora foram aos poucos se incorporando aos diversos processos de composição musical de vanguarda. Diferenças surgem então entre as abordagens de alguns compositores, derivadas principalmente no que diz respeito ao material sonoro explorado e às estratégias de manipulação. Entre tais abordagens, nomeamos aqui três delas, apontadas por Gibbs (2007), ao descrever esse processo de desenvolvimento da música eletroacústica, partindo da instituição da Rádio e através do experimentalismo de Schaeffer.

A denominada Musique Concrète de Pierre Schaeffer, na França, explorava principalmente sons gravados e manipulados através de processos artesanais com a própria fita magnética. A música eletrônica, por outro lado, decorrente dos estudos de Werner Meyer-Eppler e Herbert Eimert, em Colônia, se apropriou da exploração de osciladores e filtros e, posteriormente, de sons provenientes dos mais diversos tipos de síntese, e foi popularizada por Stockhausen (Holmes, 2008, 55). A composição de paisagens sonoras, por sua vez, direcionada pelos estudos de Murray Schafer, Barry Truax e Hilldegard Westerkamp, também exploram a manipulação de gravações, no entanto, adotando um viés ecológico e mais naturalista. Aos poucos essas três "músicas" se somaram ao que denominamos atualmente de música acusmática, sendo essa

\footnotetext{
7 "Sound Art" ou "Sonic Art".

8 Original: "So I think that music is a subset of sonic art and sonic art is a subset of soundscape and soundscape is really the world around us, virtually complete."

9 Como exemplos de "Esculturas Sonoras" podemos citar os trabalhos de Zimoun (www.zimoun.net/), Michele Spanghero (www.michelespanghero.com), Jack Pavlik e suas "esculturas sonoras cinéticas" (https://www.youtube.com/watch?v=C6hOKQL5SDA), Tonkin Liu com sua obra "Singing Ringing Tree" (http://www.tonkinliu.co.uk/project/singing-ringing-tree), ou até mesmo Martin Molin e sua "Marble Machine" (https://www.youtube.com/watch?v=IvUU8joBb1Q). Tais trabalhos se confundem em definição também com o termo "instalação sonora".
} 
terminologia usada especificamente para descrever a música fixada em suporte $(C D$, fita magnética, arquivo de áudio) e reproduzida através de alto falantes, uma das vertentes de uma totalidade de abordagens da música produzida com o auxílio do computador, denominada música eletroacústica, que englobaria ainda a música algorítmica, com processamento em tempo real, mista (parte eletrônica associada a uma parte instrumental), desenvolvimento de hiper-instrumentos, entre outras.

No que diz respeito ao processo de espacialização sonora, importante para o desenvolvimento da música eletroacústica audiovisual para $V R^{10}$, historicamente, podemos citar como primeiro concerto público a apresentar obras eletroacústicas espacializadas, aquele organizado por Pierre Schaeffer, Pierre Henry e Jacques Poullin, em maio de 1952, na Salle de L'Ancien, no conservatório de Paris. O repertório executado no mencionado concerto contava com obras tais como Timbres-durees de Messiaen (Murray, 2016), os Estudos Concretos de Boulez e Konkrete Etude de Stockhausen.

Dentre as primeiras obras compostas especificamente para sistemas de reprodução com espacialização podemos citar Pfingstoratorium: Spiritus Intelligentiae Sanctus de Ernest Krenek (1955), para um sistema estereofônico, Gesang der Jünglinge de Stockhausen (1955-1956), para cinco grupos de alto-falantes dispostos em torno do público (Menezes 1998, 22), e Poeme Életronique (1958) de Edgard Varèse. Esta última foi, provavelmente não só a composição mais icônica, mas uma experiência multissensorial completa, por explorar um sistema de áudio multicanal associado a efeitos de iluminação e projeções de slides (Gibbs 2007, 30) em um espaço arquitetônico, o Pavilhão Philips. Tanto o processo de espacialização de áudio, quanto a incorporação de elementos visuais às composições eletroacústicas, se mostram essenciais para o desenvolvimento do nosso objeto.

De uma forma semelhante à consideração de que o fonógrafo deu origem a música eletroacústica, especificamente a acusmática, o Cinema, talvez possa ser considerado um precursor das artes visuais em movimento que se utilizam de ferramentas tecnológicas, tais como a arte digital, a videoarte, as instalações visuais, as intervenções, as artes performáticas, entre outras. Segundo Gibbs, nos anos 1960 "a arte contemporânea como um todo estava em um estado de fluxo e novas formas emergiam praticamente todo dia"11 (Gibbs 2007, 32), e a combinação de áudio e vídeo, aconteceu em diversos níveis, de diversas formas, e recebeu, ao longo de todo esse tempo, diferentes terminologias.

Nessa histórica busca de identificação e definição terminológica de manifestações artísticas audiovisuais, algumas delas estão estreitamente relacionadas com o nosso objeto de estudos. A denominada Ambient Music de Brian Eno, que, apesar de originalmente somente sonora, teve diversos vídeos desenvolvidos pelo próprio compositor para acompanhá-la, é conhecida pela sua característica de ser "uma forma musical originalmente concebida para ser parte de um ambiente, sala de espera ou elevador, ao invés de ser ouvida em sua forma pura"12 (Gibbs 2007, 32). A atividade / profissão / processo denominado de Sound Design, "a

${ }^{10} \mathrm{~A}$ música eletroacústica audiovisual para $V R$ se utiliza de uma mídia audiovisual adaptativa pretendida para reprodução especificamente através de um smartphone acoplado a óculos de realidade virtual e fones de ouvido para a escuta binaural. Tal mídia pode ser reproduzida também através de um computador, no entanto, elimina a proposta de imersão possibilitada pelas condições de escuta e visualização propostas inicialmente.

${ }^{11}$ Original: "(...) contemporary art as a whole was in a state of flux and new forms emerged almost daily."

12 Original: Ambient music - "A musical form that was originally designed to be part of the sonic environment rather than to be listened to in its own right." 
criação de som com o propósito externo a si mesmo ao invés de uma autônoma obra de arte"13 (Gibbs 2007, 36), se aproxima do nosso objeto por sua estreita relação com o filme e com o cinema, apesar do termo ser utilizado também pela indústria na criação de identidade sonora de marcas.

Ainda nessa busca de compreender o território audiovisual e sua relação conceitual com a arte sonora, recorremos a Leite (2004) e à sua classificação de modalidades e modelos do audiovisual. Apesar de existirem outras classificações na literatura, escolhemos iniciar por essa autora pelo fato de suas caracterizações estarem estreitamente relacionadas com a música eletroacústica, o que se mostrará importante para a definição e expansão do conceito do nosso objeto.

Leite descreve várias situações em que a imagem e o som podem se relacionar: (1) no processo de criação de uma partitura, quando uma imagem pode dar origem à criação de materiais sonoros ou à construção de estruturas, (2) no processo de produção quando o som é concebido para uma imagem concluída ou viceversa, (3) no processo em que um som real de uma imagem é tomado como material para a composição, (4) no processo de composição onde a imagem e a música interagem entre si e são concebidos simultaneamente ou (5) quando a imagem ilustra uma música previamente composta. Dos processos apresentados pela autora, o que mais nos interessa seria o (4), onde as composições da imagem e da música são concomitantes, e vemos nele uma possibilidade de elevação da produção do audiovisual para realidade virtual ao nível artístico, ao invés de restrito a produção em massa de conteúdo ${ }^{14}$.

A autora elabora também uma distinção entre duas modalidades, a Music Video da música vídeo, que apesar da proximidade pela tradução, se apresentam como duas coisas completamente diferentes, sendo a Music Video melhor traduzida para o que conhecemos como videoclipes, direcionado a música de massa, e a música vídeo, com uma relação mais estreita com a música eletroacústica.

Realizamos essa comparação entre esses termos com o intuito de distinguir o nosso objeto de outros, mais comumente abordados por trabalhos na área da comunicação social. Trabalhos como o de Berry e Shelton (1999) também exploram o que seria categorizado como Music Video (videoclips, vídeos de músicas como os exibidos pela emissora de TV MTV), terminologia utilizada novamente por Borém (2016), quando o mesmo descreve ferramentas para sua análise (MaPAs e EdiPAs ${ }^{15}$ ).

Segundo Leite (2004) ainda, a música vídeo se apresenta como um gênero que engloba diversas modalidades do fazer musical contemporâneo que possuem relações diretas com a música eletroacústica: tape music, música mista, live electronic music ${ }^{16}$. Esse direcionamento para um objeto relacionado com a música

13 Original: Sound Design - "The creation of sound for a purpose external to itself rather than as a freestanding piece of art."

14 Pressupomos aqui uma diferença principal entre um processo de composição audiovisual com objetivo artístico e um processo direcionado a comunicação em massa, uma vez que em processos direcionados à comunicação em massa, na maioria das vezes, temos uma equipe trabalhando em função de orientações de um cliente e que muitas vezes não têm a visão do todo, sendo o trabalho baseado em padrões e clichês já testados e aprovados comercialmente.

15 MaPAs (Mapas de Performance Audiovisual) e EdiPAs (Edição de Performance Audiovisual) são ferramentas para análise de um produto audiovisual. Apesar de estarem sendo utilizadas para análise de videoclipes no trabalho apresentado por Borém, se vislumbra a utilização de tais ferramentas também para obras eletroacústicas visuais, de forma semelhante ao processo sugerido por Tagg (1982) para a análise e estruturação de obras puramente instrumentais por leigos.

${ }^{16}$ Também denominado por outros autores simplesmente de live electronics (Menezes 1996). 
eletroacústica também é desenvolvido por Kasulin (2015) e Lima (2011). Este último propõe que o termo definido por Leite, música vídeo, ao ser fixado em uma mídia seria denominado vídeo música, e se relacionaria historicamente com outras produções videográficas onde o áudio e o vídeo "se conectam de forma indissociável e não-hierárquica".

Segundo o autor, o denominado vídeo música seria uma "modalidade de produção audiovisual em que as imagens visuais e sonoras se articulam em um processo contínuo e integrado, hibridizando-se em uma obra na qual a experiência perceptiva é trans-sensorial" (Lima, 2011, 8). Ele caracteriza a vídeo música pela forte relação entre os processos, tanto de manipulação sonora da música eletroacústica quanto das imagens que as acompanham. E também, como proposto por Bethônico (1995) e Kwastek (2013), reforça a hibridização entre imagens visuais e sonoras.

O próprio autor nos apresenta alguns exemplos do que ele denomina de vídeo música, entre eles estão os trabalhos de Mary Ellen Bute (Ex.: Synchromy $n^{\circ} 4$ ), Walter Ruttman, Oskar Fischinger, Norman McLaren, Malcolm Le Grice, Michael Snow, Ken Jacobs e Abigail Child. Muitos desses autores são mencionados também em outros trabalhos, no entanto possuem seus trabalhos classificados como Visual Music ou Seeing Sound, uma outra categoria encontrada na literatura que possui características importantes na definição do nosso objeto de estudos:

A música visual pode ser definida como imagens visuais baseadas no tempo que estabelecem uma arquitetura temporal de forma semelhante à música absoluta. Normalmente é não narrativo e não representacional (embora não seja necessário). A música visual pode ser acompanhada de som, mas também pode ser silenciosa. ${ }^{17}$ (Evans $2005,11)$

Voltando um pouco para a análise desse termo, Visual Music, mais difundido nas áreas próximas às artes visuais, o gênero em si tem sua origem em produções puramente imagéticas, com características inerentemente abstratas, e provavelmente foi utilizado pela primeira vez por Roger Fry ${ }^{18}$ em 1912 para descrever a obra de artistas pós-impressionistas franceses, que seguiam exemplos de Kandinsky e Picasso (Rekvelt 2018):

(...) Eles não procuram imitar a forma, mas criar forma; não para imitar a vida, mas para encontrar um equivalente para a vida. Com isso, quero dizer que eles desejam fazer imagens que, pela clareza de sua estrutura lógica e pela sua unidade de textura, devem atrair a nossa imaginação desinteressada e contemplativa com algo da mesma vivacidade que as coisas da vida real apelam para nossas atividades práticas. Na verdade, eles não visam a ilusão, mas a realidade. O extremo lógico de tal método seria, sem dúvida, a tentativa de abandonar toda semelhança com a forma natural e criar uma linguagem de forma puramente abstrata - uma música visual; e as obras posteriores de Picasso mostram

17 Original: "Visual music can be defined as time-based visual imagery that establishes a temporal architecture in a way similar to absolute music. It is typically non narrative and non-representational (although it need not be either). Visual music can be accompanied by sound but can also be silent."

18 Pintor e crítico de arte inglês (1866-1934). 
isso com clareza suficiente. Eles podem ou não ser bem sucedidos em sua tentativa. ${ }^{19}$ (Fry 1920, 157)

No desenvolvimento da denominada Visual Music, ao longo da história, diversos artistas e cientistas investiram em experimentos que fizessem algum tipo de associação entre som e imagem, objetivando a criação de um dispositivo que funcionasse em tempo real, direcionado à performance, alguns deles gerando simultaneamente som e imagem, outros gerando somente a imagem. Provavelmente os mais conhecidos foram os que resultaram no Clavecin Ocularie de Louis Bertrand Castel (1728), no Clavilux de Thomas Wilfred (1919), no Nourathar de Mary Hallock-Greenewalt (1924) e no Lumigraph de Elfriede Fischinger (1955).

A Visual Music, apesar de ter surgido em torno desses desenvolvimentos, chega ao século XXI mais próxima então do que Andrew Hill denomina de música eletroacústica audiovisual (Hill, 2010). Segundo o autor, uma característica fundamental desse tipo de manifestação está na associação entre imagem e som, e na sua criação a partir de ferramentas de manipulação digital dos mesmos, possibilitado pelo desenvolvimento tecnológico dos computadores. Dessa forma, ele situa também, tanto a performance de VJs ${ }^{20}$ em boates, assim como o desenvolvimento de algoritmos para a visualização do espectro sonoro em uma mesma categoria. Em sua tentativa de classificar melhor seu objeto, assim como pretendemos fazer com o nosso, Hill desmembra as manifestações audiovisuais relacionadas com a Visual Music ${ }^{21}$ em quatro categorias:

A. A abordagem puramente visual da Visual Music, exemplificada pelas obras de Thomas Wilfred, Kandinsky e Klee. Obras que objetivam emular a música ou contém estruturas visuais inspiradas pelas musicais, mas que não contém som em si.

B. Composições visuais sobre uma música pré-existente como as primeiras obras de Orkar Fischinger, as interpretações artísticas de Fantasia de Walt Disney, ou videoclipes como os apresentados pela MTV.

C. A composição do som e imagem informada pelas tradições da música cujos materiais são estruturados ao longo do tempo. Esta forma é definida aqui como música audiovisual por conter elementos tanto sonoros quanto imagéticos. O som e a imagem são considerados componentes igualmente unidos no contexto de uma obra e ambos são estruturados musicalmente.

${ }^{19}$ Original: "They do not seek to imitate form, but to create form; not to imitate life, but to find an equivalent for life. By that I mean that they wish to make images which by the clearness of their logical structure, and by their closely-knit unity of texture, shall appeal to our disinterested and contemplative imagination with something of the same vividness as the things of actual life appeal to our practical activities. In fact, they aim not at illusion but at reality. The logical extreme of such a method would undoubtedly be the attempt to give up all resemblance to natural form, and to create a purely abstract language of form - a visual music; and the later works of Picasso show this clearly enough. They may or may not be successful in their attempt."

20 "VJing é a manipulação ou seleção de recursos visuais, da mesma forma que o DJing é uma seleção e manipulação de áudio. Um dos elementos-chave na prática do VJing é a mistura em tempo real de conteúdo de uma 'biblioteca de mídias'. Além da seleção de mídia, o VJing implica principalmente em processamento em tempo real do material visual. O termo também é usado para descrever o uso performativo de software generativo." Original: "VJing is the manipulation or selection of visuals, the same way DJing is a selection and manipulation of audio. One of the key elements in the practice of VJing is the realtime mix of content from a "library of media." In addition to the selection of media, VJing mostly implies realtime processing of the visual material. The term is also used to describe the performative use of generative software." (375 Wikipedians 2010, 17f)

${ }^{21}$ Aqui o autor agrupa o que é denominado de visual music, absolute film, cinedance, light shows, lumia, videomusique, e audiovisual music em gêneros que objetivam a exploração a estruturação de material visual de uma forma musical. 
D. A síntese de materiais visuais através de algoritmos a partir do som e da representação do som visualmente. Essa categoria inclui softwares de visualização tais como os encontrados no Windows media player, osciloscópios e algoritmos computacionais que renderizam visualmente a forma de onda ou o espectrograma de um material sonoro.

Assim como em Hill, nosso maior interesse está na categoria $C$, onde os artistas / compositores têm, através de aparatos tecnológicos digitais, a possibilidade de criar ambas as partes visual e sonora de suas obras audiovisuais concomitantemente, através de um processo criativo que transite entre os dois suportes, ao invés de serem concebidos de forma independentes. Dessa forma o artista tem potencial para um total controle do material, das ferramentas de manipulação e do resultado final de seu trabalho. Considerando isso podemos então enumerar as características principais do nosso objeto de estudos:

A. Origem na música eletroacústica e afastamento do produto final de possíveis semelhanças com o produzido pela indústria do cinema ou de videoclipes;

B. Material audiovisual final gerado a partir da manipulação, pelo compositor, de materiais primários gravados ou sintetizados, através de recursos tecnológicos, na maioria das vezes com o auxílio de um computador;

C. Produto final fixado em uma mídia, possibilitando o maior controle do compositor do material apresentado ao ouvinte.

Com essas características podemos observar que, tanto a música vídeo quanto a vídeo música e a Visual Music são nomenclaturas válidas. Apesar disso, adotaremos o termo música eletroacústica audiovisual ${ }^{22}$ para definir e expandir o nosso objeto de estudos, pelo simples fato de este ser um termo mais descritivo e claro. Tanto o termo música vídeo quanto o vídeo música podem ser confundidos pelos videoclipes se traduzidos para o inglês, o que pretendemos evitar, e a Visual Music possui, historicamente, uma grande ênfase no visual, o que também não é o nosso desejo.

\section{Música eletroacústica audiovisual para VR: híbrido de vídeo-música e arte sonora em um ambiente virtual}

Precisamos ter em mente que, enquanto a nossa visão é limitada inicialmente a $180^{\circ}$, podendo ser ampliada com movimentos de cabeça, a nossa audição é perifônica, ou seja, tem a característica de estar sempre recebendo sinais dos $360^{\circ}$ ao nosso redor, de cima e de baixo. As manifestações artísticas audiovisuais têm, até hoje, explorado essas características fisiológicas sem que o espectador, maravilhado com as novidades tecnológicas, questione a coerência do que lhe é apresentado. Seguindo o proposto por Schaeffer (2010), antes de poder efetivamente contribuir com uma nova estética artística, o instrumento almeja transmitir a arte da forma mais fiel possível, desafiando suas limitações. Nesse processo identificamos então o que outras mídias deixam a desejar, ou seja, as limitações que elas apresentam que as impedem de alcançar a fidelidade na representação.

Imagine uma tela de projeção de cinema, com um sistema de reprodução de áudio em 5.1. Ouvimos sons de helicópteros vindos de trás em direção a tela. A primeira contradição que podemos apontar está no fato de

\footnotetext{
${ }^{22}$ Essa música eletroacústica audiovisual será reproduzida através de uma mídia audiovisual adaptativa para realidade virtual, objeto principal do nosso trabalho de doutorado, que engloba aplicações inclusive além da presente definição.
} 
não termos caixas, nesse sistema de reprodução de áudio, sobre a cabeça do ouvinte, o que poderia fazer tal movimento mais convincente. Outra incongruência com relação a imagem pode ser observada no fato de que, se virarmos nossa visão para trás, não veremos tal helicóptero ${ }^{23}$. Obviamente a adoção de sistemas de projeção visual e de reprodução de áudio obedecem a uma série de demandas mercadológicas, de disponibilidade tecnológica, entre outras coisas. Com isso, queremos apontar aqui as deficiências de tais sistemas quando da necessidade de representar uma realidade que já conhecemos.

Uma novidade na reprodução videográfica, que se popularizou pouco antes do $V R$, foi o denominado vídeo 3D, que, com a ajuda de um óculos, nada mais é do que uma ampliação da noção de perspectiva, e que não chega realmente a envolver o espectador nas três dimensões (largura, altura e profundidade), como a sua denominação propõe, por ainda não apresentar qualquer material atrás, em cima ou embaixo do espectador. Os desenvolvimentos na área do áudio por sua vez já possibilitam há muito tempo, pelo menos a partir de meados da década de 1970, que, através de sistemas multicanais de reprodução de áudio, o espectador seja imerso em um campo sonoro tridimensional. Tais desenvolvimentos incluem o Dolby Surround 5.1 explorado comercialmente no cinema e nos Home Theaters, o sistema Ambisonics ${ }^{24}$ desenvolvido por Michel Gerzon e até mesmo sistemas binaurais de reprodução sonora para fones de ouvido que possuem experimentos datados de 1920, na Bell Labs por Harvey Fletcher, e que se popularizou através de um áudio gravado com uma Dummy Head (manequim no formato de cabeça e torso com microfones no lugar dos tímpanos) de uma visita sonora virtual ao cabelereiro, conhecida como "virtual barber shop".

Algumas das limitações mencionadas acima das mídias (ou dos sistemas) utilizadas para reprodução de material audiovisual, se apresentam como obstáculos técnicos colocados à configuração de um ambiente imersivo de projeção audiovisual que não permite correlacionar diretamente eventos visuais com eventos sonoros. Incoerências como as apontadas são responsáveis por gerar espectadores com pouco ou nenhum senso crítico, por outro lado, pode-se dizer que elas estimulam a criatividade. Ouvir um objeto sonoro sendo reproduzido acima do ponto de escuta, sem que nele tenhamos um objeto visual pode ser interessante até certo ponto, onde a tecnologia deixa de ser novidade e tal fenômeno passa a ser completamente incoerente.

Já observamos, na produção do que chamamos de mídia audiovisual adaptativa, inúmeras produções para realidade virtual com o áudio ainda em formato estereofônico (ou até monofônico), inúmeras incoerências nesse domínio do espaço extrínseco ${ }^{25}$. Entendemos a novidade que a produção audiovisual para realidade virtual ainda representa, no entanto, ferramentas para o desenvolvimento de áudio tridimensional estão

${ }^{23} \mathrm{Na}$ literatura o que denominamos aqui de incongruências, entre elas o denominado som off screen definido por Chion (1994), podem se apresentar como recursos estéticos. Não os desprezamos. No entanto, o objetivo de imitar a realidade fica a desejar se pensarmos no percurso das novas mídias proposto por Schaeffer.

${ }^{24} \mathrm{O}$ sistema Ambisonics consiste em um formato multicanal hierárquico em que uma fonte sonora monofônica espacializada pode ser codificada matematicamente em componentes relativas aos eixos $\mathrm{X}, \mathrm{Y}$ e $Z$, que combinadas com uma componente omnidirecional W, transmite a informação posicional. Tal conteúdo espacializado dessa forma pode ser decodificado para qualquer arranjo de alto-falantes na etapa de reprodução.

${ }^{25}$ Consideramos aqui o conceito de espaço extrínseco adotado por Henriksen (2002): "o espaço extrínseco tem a ver com o som no espaço. Refere-se ao espaço que envolve o som como resultado de seu comportamento espacial e sua interação com o ambiente em que ele existe. $O$ espaço extrínseco é percebido em termos de movimento, distância e direção dos sons. A localização no espaço físico e / ou virtual é baseada no espaço extrínseco". (Henriksen 2002, 18, grifo nosso). 
cada vez mais populares e em sua grande maioria gratuitas. Uma elaboração de áudio tridimensional para vídeos para $V R$ ainda não é prioridade da maioria e apontamos como principais motivos: as exigências da indústria pela alta velocidade em que se deve ser disponibilizado o material audiovisual, sobrando pouco tempo para um tratamento cuidadoso do áudio; a ênfase histórica e ainda hegemônica do visual sobre o sonoro; e a falta de conhecimento estético para explorar os recursos de mixagem de áudio tridimensional, assim como outras possíveis relações entre ambas as mídias.

Seguindo o que Schaeffer (2010) propõe com relação aos três níveis de desenvolvimento de uma nova mídia, depois de passado o momento em que ela é admirada como novidade, sua busca em direção a representação da realidade para depois poder se tornar um instrumento artístico, exige que ela seja o mais congruente possível. Na busca pelo desenvolvimento de material audiovisual ao terceiro nível proposto por Schaeffer, onde a técnica informa a arte, esses paradoxos se tornam obstáculos pois, em seu segundo nível, já observamos tais imperfeições, incapacidades de corresponder à realidade. Uma vez essas imperfeições superadas e a aproximação da realidade sendo possível no novo aparato tecnológico, as portas realmente se abrem para a criação artística. Através de mídias audiovisuais tridimensionais adaptativas para a realidade virtual, uma projeção visual tridimensional, associada a uma reprodução de áudio também tridimensional, tende a minimizar as contradições, como as descritas acima, também observadas em outras mídias, e deixa o compositor livre para explorar o material em um nível semântico, inclusive criando contradições propositalmente, dentro do contexto de sua obra.

Nesse novo aparato, nessa mídia emergente, a exploração do espaço tridimensional apresentado pelo audiovisual, assim como sua interatividade (por mais trivial que seja), respondendo aos movimentos da cabeça do ouvinte e possibilitando uma maior imersão, possui papel crucial no desenvolvimento e na criação de uma retórica da utilização do espaço que incite significados para o espectador. Na produção de audiovisual para $V R$ vemos então a possibilidade do fim das incoerências técnicas, onde dispomos de um sistema completo de reprodução tridimensional imersivo e responsivo, em que uma composição eletroacústica audiovisual que explore tais possibilidades se aproxima de uma instalação audiovisual inserida em uma outra realidade.

Apesar da proposta inicial de explorarmos uma mídia audiovisual adaptativa como produto final, alguns podem argumentar com relação a necessidade de aprimoramentos, observáveis em qualquer sistema com o qual viermos a trabalhar. Considerando isso, podemos pensar na possibilidade de que a produção de música eletroacústica audiovisual para $V R$ explore as mídias audiovisuais adaptativas já com a consciência de futuros aprimoramentos, se garantindo através da criação e armazenamento em formatos com altas resoluções, a serem exploradas em outros contextos ou outros sistemas ${ }^{26}$.

\section{Produção de estudos de música eletroacústica audiovisual para VR}

Durante o período do doutorado, realizamos a produção de duas obras, na verdade um conjunto de cinco estudos (explorando somente imagens sintetizadas que são contrastadas com elementos sonoros gravados e manipulados) e um outro estudo isolado (explorando uma situação oposta, imagens gravadas contrapostas

\footnotetext{
${ }^{26}$ Consideramos aqui a possibilidade de obras compostas para múltiplas telas a serem posicionadas ao redor do ouvinte, assim como para sistemas multicanais de áudio tridimensional baseados em Ambisonics de ordens elevadas, por enquanto ainda limitadas à reprodução via plataformas de streaming que utilizam somente Ambisonics de primeira ordem.
} 
a sons sintetizados), apresentando características contrastantes e que explorassem as ferramentas e estéticas estudadas. Através deles objetivamos a demonstração de algumas estratégias de relação entre imagem e som propostas, e que representassem o que propomos como música eletroacústica audiovisual para $V R$.

Em ambos os estudos, gestos no denominado espaço extrínseco se apresentam de forma ora em conformidade, ora em controvérsia, ora em complementação (Cook, 1998), explorando possíveis relações entre o nível sonoro e o imagético. Não entraremos em detalhes com relação às ferramentas utilizadas no processo, mas apontaremos links para estudos sobre as mesmas ${ }^{27}$. Com isso pretendemos focar nas possibilidades estéticas observadas pelo desenvolvimento de um ambiente virtual para trabalhos com som e imagem em $360^{\circ}$.

\section{1. cinq études pour une autre réalité}

Esses cinco estudos têm como inspiração os cinco primeiros estudos de Schaefer ${ }^{28}$ no título $^{29}$, como primeira abordagem dentro de uma manifestação artística emergente. Com cerca de 2 minutos cada, os estudos exploram material visual sintetizado no software Mandelbulb ${ }^{30}$, sendo os estudos "changer d'arches" ${ }^{31} \mathrm{e}$ "sur basse résolution" 32 tendo sido montados utilizando o Adobe Premiere, e os estudos "d'origine organique" 33 , "dans le désert" 34 e "d'or nous portons la poussière" 35 montados no Sony Vegas.

No estudo "sur basse résolution", de uma forma geral, existe uma exploração de um espaço ambiofônico (Vande Gorne, 2002), através de uma textura direcionada completamente para o canal W do campo sonoro em Ambisonics de primeira ordem, a transformando em um elemento envolvente e imutável. Um espaço fonte (Vande Gorne, 2002) é explorado no gestual e na movimentação de outros objetos sonoros. Em alguns trechos se objetivou a criação de uma certa granulação do material sonoro no espaço extrínseco (1'05", 1'35" 1'52', 2'00', 2'13'), em concordância com o material visual.

\footnotetext{
27 Nos trabalhos apresentados exploramos diversos desses plug-ins direcionados para o processamento da espacialização sonora através de sistemas baseados em Ambisonics. Entre eles se destacam o "ATK for Reaper" (https://www.ambisonictoolkit.net/documentation/reaper/), o "FB360" (https://facebook360.fb.com/spatial-workstation/), o "o3acore" da Blue Ripple Sound (https://www.blueripplesound.com/products/o3a-core) e o "Ambix" de Matthias Kronlachner (http://www.matthiaskronlachner.com/?p=2015).

28 "5 Etudes de Bruits", trad.: "cinco estudos de ruído".

${ }^{29}$ Exemplo de exploração e da importância da matriz verbal (Santaella, 2001), como um terceiro elemento na música eletroacústica audiovisual.

${ }^{30}$ http://www.mandelbulb.com/2014/mandelbulb-3d-mb3d-fractal-rendering-software/

31 Tradução: "mudando em arcos".

32 Tradução: "em baixa resolução".

33 Tradução: "de origem orgânica".

34 Tradução: "no deserto".

35 Tradução: "de ouro carregamos o pó".
} 
Na realização do processo de granulação em específico, exploramos a aplicação de uma modulação dos parâmetros azimuth e elevation ${ }^{36}$ do plugin ${ }^{37}$ utilizado aplicado ao material sonoro, para se alcançar uma certa concordância com alguns objetos audiovisuais que se apresentam de forma muito rápida, como flashes. Por chamar muito a atenção do ouvinte para movimentos bruscos, tal manipulação foi utilizada com parcimônia.

Em 1'35" realizamos uma granulação em um objeto sonoro sendo que seu objeto visual correspondente apresenta características estáticas, tal estranhamento, proveniente de uma relação de discordância, destaca um objeto que tem uma única aparição no estudo. Nos instantes 1'52', 2'00' e 2'13' podemos observar um exemplo de como um objeto sonoro, já reconhecido correspondente a um objeto visual, continua o trajeto do mesmo sem que ele esteja visível, ilustrando uma relação de complementação entre o visual e o sonoro, nesse domínio do espaço extrínseco, exemplo também do princípio de continuidade apresentado por Bregman (1990).

No estudo "d'origine organique" apresentamos duas texturas principais, uma mais grave e outra com características granulares. A primeira delas foi direcionada diretamente para o canal $\mathrm{W}$ do campo sonoro em Ambisonics, se apresentando onipresente, criando um espaço ambiofônico, enquanto a segunda foi espacializada aleatoriamente, de forma concordante com suas características intrínsecas, através da automação dos parâmetros azimuth e elevation. Como o pacote de plugins adotado não oferece a possibilidade de exploração de um gesto de atravessar, por não apresentar nenhum tipo de simulador de efeito Doppler ${ }^{38}$, muitos dos gestos visuais que atravessariam o espectador tem seu gesto sonoro correspondente espacializado de forma frontal subindo ou descendo no campo sonoro 3D (ex. 2'42", 2'47", 3'03', 3'30'). Gestos sonoros concordantes com um objeto visual específico tais como em 3'00", 3'11" e 3'39" foram espacializados para condizer com seu correspondente visual, assumindo uma abordagem de replicação (Begault, 2000).

No estudo "dans le désert" exploramos, em uma textura granular que percorre a obra, uma espacialização sonora coerente com o visual através de automação, e à algumas texturas visuais onipresentes (5'13", 5'22" e 6 $6^{\prime} 18^{\prime \prime}$ ) foram aplicados algum movimento, em discordância com o visual, com o intuito de chamar a atenção do ouvinte para as mesmas, uma vez que os gestos sonoros que permeiam a peça podem se mostrar monótonos. Gestos sonoros espaciais foram explorados para gerar rupturas entre texturas visuais com características diferentes $\left(5^{\prime} 28^{\prime \prime}, 6^{\prime} 09^{\prime \prime}\right)$ ou mudanças de direção observada em seu conteúdo intrínseco $\left(5^{\prime} 52^{\prime \prime}, 5^{\prime} 56^{\prime \prime}\right)$.

${ }^{36} \mathrm{O}$ parâmetro azimuth é definido por um ângulo no plano horizontal em referência ao ouvinte no qual posicionamos uma fonte sonora. Inicialmente temos como a frente do ouvinte sendo $0^{\circ}$ e trás $180^{\circ}$. Dependendo da ferramenta esse ângulo dá a volta do ouvinte indo do $0^{\circ}$ ao $360^{\circ}$ ou de $0^{\circ}$ a $180^{\circ}$ e $-180^{\circ}$. Elevation se refere a outro parâmetro referente ao ângulo de altura, sendo normalmente $0^{\circ}$ associado à frente, $90^{\circ}$ acima do ouvinte e $-90^{\circ}$ abaixo do ouvinte.

37 O plugin é um tipo específico de software que podemos incluir em uma DAW (Digital Audio Workstation) ou estação de trabalho de áudio digital, para realizar o processamento de uma trilha específica de áudio digital.

38 O efeito Doppler consiste em uma alteração no pitch (altura) de uma fonte sonora para melhor simular sua movimentação. Tal efeito se mostra essencial em gestos espaciais que pretendem simular uma passagem da fonte sonora pelo espectador (através dele) que se encontra no centro do campo sonoro criado. 
No estudo "changer d'arches", o movimento de atravessar o expectador, apresentando uma concordância entre o material visual e sonoro, possibilitado pelo plugin escolhido foi amplamente explorado ao longo da peça como pode ser observado em 6'53", 6'57', 7'22' e 7'34" por exemplo. Em diversos momentos a partir de 7'31" exploramos o que Chion (1994) denominaria de som diegético off screen ${ }^{39}$. Apesar de estarmos trabalhando com os $360^{\circ}$ tanto visual quanto sonoro, sons que estão relacionados com a temática da obra, mas não são visualizados, receberiam essa denominação, e podem ser observados no som de martelos batendo, peças de metal caindo, entre outras, que não se mostram visíveis.

Nessa obra optamos por não colocar as texturas diretamente no canal W do campo sonoro Ambisonics ${ }^{40}$, como fizemos em algumas outras para dar a sensação de envolvimento ao ouvinte. Em contrapartida, realizamos a automação de seu movimento, muito sutil na maioria das vezes, explorando principalmente o parâmetro distância, abrimos a possibilidade de chamar a atenção do ouvinte, através do movimento, para algo que supostamente seria uma constante. Efeitos de desmanchar, como observado em 7'11" também foram realizados através de automação do parâmetro distância, outra possibilidade observada seria a de se realizar uma granulação com mais parâmetros, tais como o azimuth e elevação, o que foi realizado em outros estudos.

No estudo "d'or nous portons la poussière", duas texturas principais, que separam a obra em duas seções, e que se pretendiam sem uma direção determinada foram direcionadas exclusivamente para o canal $\mathrm{W}$ do decodificador. Os gestos principais de atravessar o expectador foram realizados explorando a simulação do efeito Doppler do plugin adotado. A obra como um todo possui características predominantemente texturais, e em decorrência disso, os poucos gestos são extremamente significativos e chamam a atenção do ouvinte de forma mais intensa.
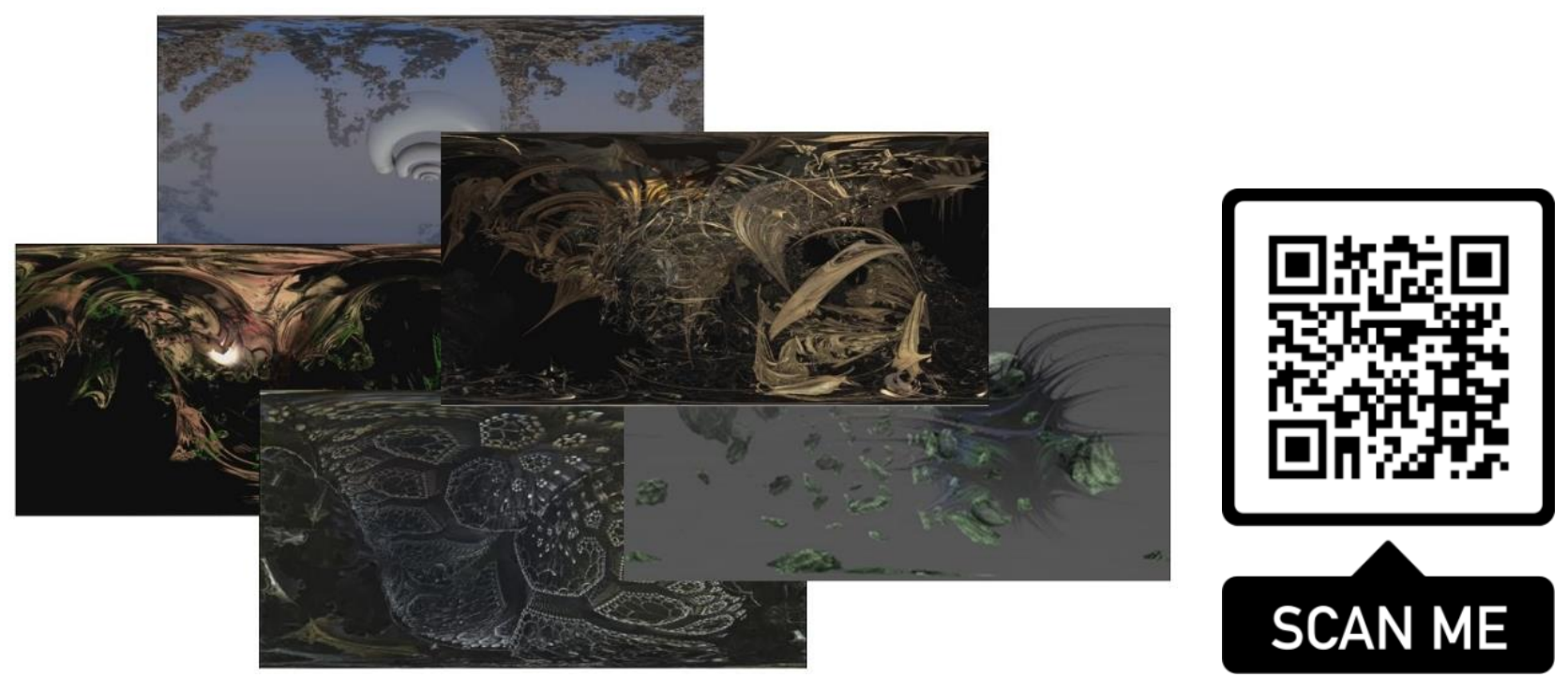

Figura 1 - Frames de cada um dos cinco estudos e QR Code para link ${ }^{41}$

${ }^{39}$ Chion define o som "diegético" como aquele som que faz parte da narrativa; e como som off screen aquele que não podemos ver na imagem projetada na tela.

$40 \mathrm{O}$ canal $\mathrm{W}$ de um campo sonoro criado em Ambisonics se refere ao componente omnidirecional do sistema, ou seja, aquele conteúdo sonoro que não foi especializado, não possui informação de direcionalidade, sendo reproduzido igualmente por todos os alto-falantes do sistema.

${ }^{41}$ https://youtu.be/rz4ENoCMdKQ 
São apresentados basicamente dois gestos no domínio do espaço extrínseco, o de atravessar e o granular, sendo o primeiro mais predominante e o segundo explorado nos flashes observados em $10^{\prime} 24^{\prime \prime}$ e $10^{\prime} 28^{\prime \prime}$ por exemplo. Nem sempre os gestos de atravessar fazem a trajetória frente-trás como seria mais evidente, mas eventualmente a trajetória de esquerda-direita, como em 11'00'. Algum movimento mais aleatório, que evidenciasse o efeito Doppler do plugin, foi explorado, mas em controvérsia com o material visual, como em 9'49" e 9'52. Outra controvérsia pode ser observada em 9'59' onde o espaço extrínseco do material sonoro se apresenta de forma estática, apesar da movimentação visual.

\subsection{From the inside}

Essa obra consiste de um breve estudo com aproximadamente dois minutos de duração que explora as possibilidades de uma câmera $360^{\circ}$ como geradora de material visual tridimensional. A maior dificuldade encontrada no processo foi a utilização da câmera para a geração de imagens interessantes do ponto de vista artístico. Isso se dá principalmente pelo fato de que sua característica mais individual, a de gravar em $360^{\circ}$, se apresenta também como o seu maior problema, uma vez ser quase impossível realizar uma gravação descompromissada, sem que tenhamos pessoas olhando diretamente para a câmera ou que não apresentem o próprio operador no material visual. Para uma gravação realista ela se mostra a ferramenta perfeita, como observado em diversos outros projetos. No entanto, para a composição de música eletroacústica audiovisual, encontrar situações em que o material gravado se aproxime do abstrato (parâmetro adotado como poética composicional), sem evocar diretamente a algo conhecido e que não trouxesse consigo um referencial semântico já definido, foi extremamente difícil.

Uma estratégia encontrada para solucionar isso foi a de se explorar o interior de objetos encontrados dentro de casa, entre eles: armários, panelas, sacolas plásticas, vidros, caixas, que pudessem esconder o seu entorno da própria câmera. Nessa escolha foi importante considerar que os objetos não podiam ser completamente foscos, uma vez que, sem luz não podemos ter a formação da imagem na câmera - princípio básico da fotografia de que necessitamos de luz incidindo no objeto para que sua reflexão forme imagens visíveis.

Uma vez que o material sonoro proveniente da própria gravação da câmera ou eram muito baixos ou nulos, ou simplesmente não possuíam informação suficiente ou interessante para serem trabalhados de forma criativa, o material sonoro a ser desenvolvido na obra foi uma questão que demandou muita reflexão. Optamos por explorar sons sintetizados que, pelo fato de se apresentarem distantes semanticamente do material intrínseco visual, se mostrou a opção mais interessante, sendo inclusive um elemento de contraste natural. Uma vez que não seria encontrada qualquer coerência entre o material sonoro e visual do ponto de vista da natureza do material em si, buscamos atingir uma coerência composicional no domínio do espaço extrínseco.

Na obra são exploradas basicamente 12 texturas visuais diferentes e, associada a elas, respectivas texturas sonoras. No entanto, em determinados momentos, suas aparições são rápidas o suficiente para poderem ser observadas como gestos sonoros ou visuais. Além das texturas, 3 gestos sonoros são associados diretamente a aparição de três dos elementos visuais. O maior interesse do estudo surge na forma como tais texturas e gestos audiovisuais se apresentam no espaço extrínseco em ambas as dimensões visual e sonora, ou seja, em onde cada elemento surge em relação ao espectador. 
O estudo apresenta um percurso aparentemente caótico por dentro dos objetos escolhidos, onde eles são eventualmente processados e superpostos em diferentes combinações. Em uma narrativa gestualcoreográfica (Baalman 2010) são apresentados abaixo alguns dos momentos mais significativos para ilustrar as relações de conformidade ou controvérsia dos materiais sonoros e visuais tanto no domínio do material quanto do espaço extrínseco.

Em 0'49" uma textura sonora associada a uma imagem desfocada em movimento de rotação apresenta um gesto de salto no domínio sonoro, chamando muita atenção para um elemento visualmente pouco evidente. A textura sonora associada à visualização de dentro de um recipiente metálico perfurado, apresenta, em três momentos distintos, 0'34', 1'05" e 1'34', movimentação no espaço extrínseco em controvérsia com o material visual, trazendo a atenção para um elemento, inicialmente em segundo plano.

Em 0'15" a textura sonora associada a visualização obtida do interior de uma construção de plástico escura, em uma relação de contraste, se mostra com um movimento de rotação no espaço extrínseco bem lento enquanto o visual faz rotação rápidas; em $0^{\prime} 18^{\prime \prime}$, novamente em uma relação de contraste, a rotação do evento sonoro se mostra mais lento e em sentido contrário ao visual; em 0'24", explorando relações mais complexas que se modificam ao longo de apenas 10 segundos, a textura sonora percorre três movimentos com sentidos diferentes, inicialmente realizando uma rotação mais lenta que o visual e em sentido contrário, em um segundo momento, mais rápida que o visual e no mesmo sentido, inclusive com modificações no material que se aproximam mais da movimentação visual do que a própria movimentação no domínio do espaço extrínseco, e em um terceiro momento, novamente em sentido contrário e mais lento. Em 0’39" essa mesma textura retorna, dessa vez apresentando um movimento de rotação completamente coerente entre o visual e o sonoro, rápido e na mesma direção. Em 1'19'" essa textura volta se apresentando coerente com o material visual tanto em seu movimento de rotação, que se inicia lento e vai acelerando, até ser interrompido pela textura que se segue, quanto em seu material que apresenta modificações que guiam tal percepção. Em 1'27' ressurge um contraste, enquanto o visual se apresenta com uma movimentação lenta, o espaço extrínseco se encontra completamente estático e o nível material com uma agitação extremamente alta. Em 1'39" uma nova conformidade se apresenta tanto no espaço extrínseco sonoro e visual quanto no domínio do material.

Em 0'46", 1'05", 1'11" e 1'32' temos uma textura sonora associada a uma imagem visual obtida de dentro de uma estrutura escura circular e estática. Em todas as aparições realizamos uma movimentação no espaço extrínseco do material sonoro explorando um gestual granular, em contraste com a parte visual, completamente estática. Apesar de dissonante, tal realização, de certa forma, reforça a associação, inicialmente imprevisível.

Em 1'14" uma textura sonora associada a uma textura visual obtida com a gravação de dentro de um vidro canelado, realiza um movimento de rotação tanto em sentido contrário ao do visual, quanto em uma velocidade diferente, ilustrando, nesse caso uma controvérsia. Essa mesma textura reaparece em 1'21', 1'30" e 1'46", e é apresentada, no domínio do espaço extrínseco, como estática, apesar de um certo movimento lento no correspondente visual. A granulação do vidro canelado da imagem se mostra em concordância com uma certa granulação do material sonoro escolhido, no domínio de constituição do material.

A textura sonora associada ao interior de um objeto feito de fios marrons trançados, apresentada em $0^{\prime} 16^{\prime \prime}$, 0'21', 0'26", 0’32' e 1'37' explora, no domínio do espaço extrínseco, um gestual em forma de ondas, em 
concordância com a movimentação do seu componente visual. No domínio da constituição do material podemos observar o contraste entre um material sonoro também em forma de ondas, enquanto que no visual os elementos se aproximariam mais de um material granular.

O material sonoro apresentado em $0^{\prime} 50^{\prime \prime}, 0^{\prime} 54^{\prime \prime}, 0^{\prime} 58^{\prime \prime}$ e $1^{\prime} 45^{\prime \prime}$, associado visualmente com o interior de aparelhos domésticos, possui uma característica granular, no domínio da constituição de seu material, em discordância com o seu espaço extrínseco, completamente estático. Por sua vez, tal 'estaticidade', se mostra em concordância em ambos os níveis do material visual.

Os gestos sonoros, associados ao abrir das portas em $0^{\prime} 01^{\prime \prime}, 0^{\prime} 10^{\prime \prime}, 1^{\prime} 53^{\prime \prime}$ e 1'56", ao aparecimento da cachorrinha em 0'26' e 0'29', e à sacola marrom com o logo vermelho em 0'43', 0'50', 0'56', 1'01', 1'08' e 1'14", foram espacializados de forma a condizer com suas correspondentes visuais, buscando uma certa replicação espacial.

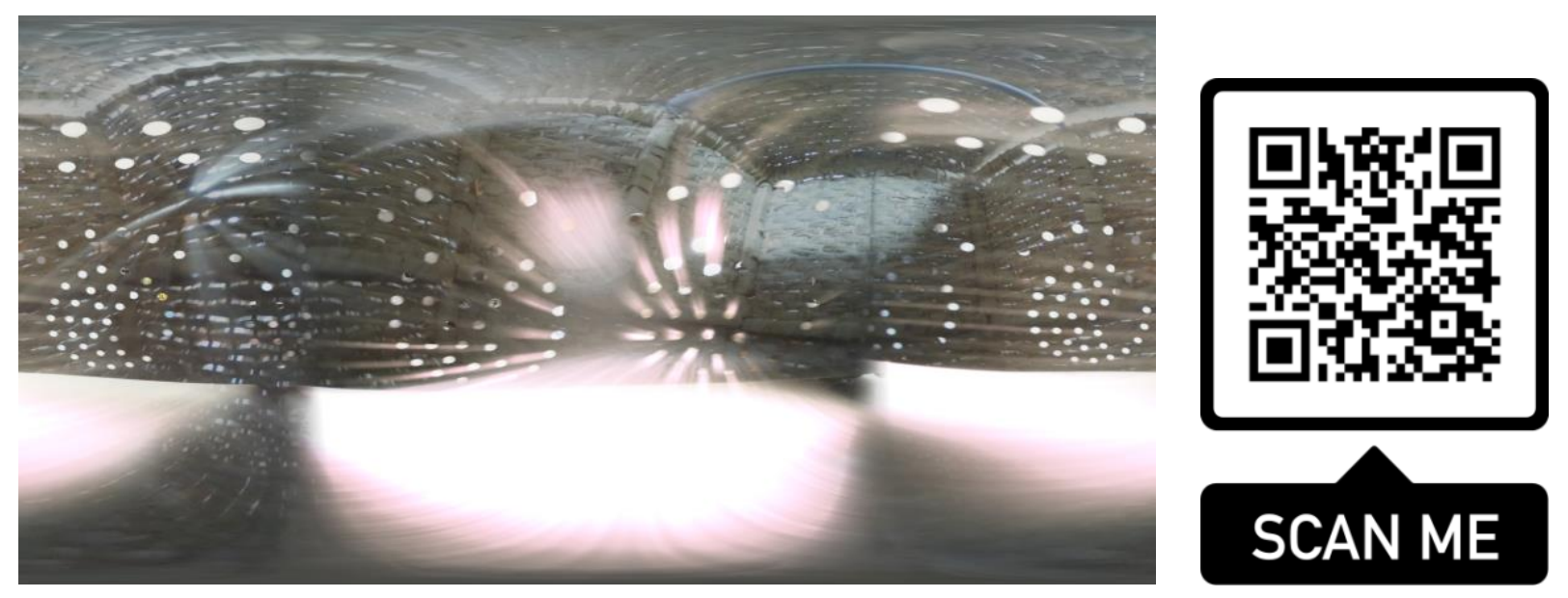

Figura 2 - Frame do estudo From the Inside e QR Code para link ${ }^{42}$

\section{Conclusão e pesquisas futuras}

Com esse trabalho pretendemos consolidar e ampliar o acesso ao que denominamos de música eletroacústica audiovisual para $V R$, assim como apontar estratégias de exploração do material nessa manifestação artística emergente. A característica de termos uma certa integridade do espaço extrínseco tanto nas etapas de produção quanto de reprodução de uma mídia fixa direcionada para fones de ouvido e telas de smartphones acoplados a óculos de realidade virtual, possibilita a criação de relações entre outros parâmetros sonoros e visuais que são objetos de estudos em andamento. Uma vez bem definido e ilustrado a terminologia adotada aqui, partiremos para a consolidação de outros termos e estratégias.

Entre as principais características dessa modalidade emergente apontamos: a possibilidade de imersão, tanto sonora quanto visual, na obra criada; a proximidade dos resultados obtidos nos processos de criação e reprodução, sendo a mídia e o dispositivo de reprodução, um fator em comum; a possibilidade de criação de uma retórica dos gestos espaciais tanto sonoros quanto visuais; o total controle sobre o resultado final da obra, sem o intermédio de um intérprete, o que já é uma característica inerente à diversas vertentes da música eletroacústica, aqui apresentada de forma bem evidente; a criação e controle de material sonoro e visual de forma perifônica, ou seja, nos $360^{\circ}$ ao redor do espectador, com altura; o fácil acesso à obra, uma

42 https://www.youtube.com/watch?v=gV8W6KzFuzM 
vez que plataformas de streaming atuais estão se preparando para a reprodução de mídias adaptativas e de forma gratuita.

Apresentamos dois estudos desenvolvidos principalmente com o intuito de exemplificar as possibilidades nesse mundo virtual, onde tanto o áudio quanto as imagens podem ser trabalhadas de forma a envolver o espectador nos seus $360^{\circ}$ possíveis em ambos os domínios de percepção. Com essa ampliação do que é apresentado ao espectador, novas estratégias composicionais surgem, e um maior controle do material é colocado à disposição do compositor.

Entre tais estratégias, apontamos a possibilidade de outras relações entre os materiais sonoros e visuais a partir da manipulação do espaço extrínseco, a possibilidade do compositor atuar também como artista visual ou estabelecer parcerias, e a utilização do computador como principal ferramenta de composição, sendo os smartphones, agora, a principal via de reprodução e distribuição das obras criadas nesse contexto. Tais estratégias nos apontam para estudos relacionados à influência dessas novas tecnologias tanto de criação quanto de reprodução na cultura musical da sociedade, assim como na própria formação do compositor contemporâneo.

\section{Referências bibliográficas}

375 Wikipedians. 2010. VJing. Greyscale Press.

Baalman, Marije. 2010. "Spatial Composition Techniques and Sound Spatialization Technologies". In.: Organised Sound, 15 (3) 209-218. United Kingdom: Cambridge Press.

Begault, Durand. R. 2000. 3-D Sound for Virtual Reality and Multimidia. Moffett Field, California: Ames Research Center / NASA.

Berry, Venise, e Vanessa Shelton. 1999. "Watching Music Interpretations of Visual Music Performance". In.: Journal of Communication Inquiry, 23 (2): 132-151. SAGE Social Science Collections.

Bethônico, Jalver. 1995. "Comunicação visual e comunicação sonora: uma relação semiótica." Master dissertation, Minas Gerais, BR: Universidade Federal de Minas Gerais.

Bethônico, Jalver. 2001. A Articulação dos Signos Audiovisuais. Doctoral dissertation, São Paulo, BR: Pontifícia Universidade Católica.

Borém, Fausto. 2016. "MaPA e EdiPA: Duas Ferramentas Analíticas para as Relações Texto-Som-Imagem em Vídeos de Música". In.: Musica Theorica, Salvador: TeMA: 1-37.

Bregman, Albert S. 1990. Auditory Scene Analysis: The Perceptual Organization of Sound. Cambridge: MIT Press.

Chion, Michel. 1994. Audio-Vision: Sound On Screen. Ed. Claudia Gorbman. New York: Columbia University Press.

Cook, Nicholas. 1998. Analyzing musical multimedia. Oxford: Oxford University Press.

Evans, Brian. 2005. "Foundations of a Visual Music". In.: Computer Music Journal, 29 (4): 11-24. Massachusetts Institute of Technology.

Ferreira, Aurélio Buarque de Holanda. 1986. Novo Dicionário da Língua Portuguesa. 2. ed. re. aum. Rio de Janeiro: Nova Fronteira. 
Fry, Roger Eliot. 1920. Vision and Design. London: Chatto \& Windus. https://archive.org/details/visiondesign00fryr.

Gibbs, Tony. 2007. The Fundamentals of Sonic Art and Sound Design. Switzerland: Ava.

Henriksen, F.E. 2002. "Space in electroacoustic music: composition, performance and perception of musical space." Doctoral dissertation, London, UK: City University.

Hill, Andrew. 2010. "What is Electroacoustic Audio-Visual Music? Nomenclature and Cognition". In.: Proceedings of Sound, Sight, Space and Play. Anais. De Montford University Leicester, United Kingdom.

Holmes, Thom. 2008. Electronic and experimental music: technology, music, and culture. 3rd ed. New York: Routledge.

Kasulin, Aitana. 2015. "Video-música entre la conceptualización y la práctica." Master dissertation, Buenos Aires, AR: Universidad de Buenos Aires.

Kwastek, Katja. 2013. Aesthetics of Interaction in Digital Art. Cambridge: MIT Press.

Leite, Vania Dantas. 2004. Relação som/imagem: um estudo da relação som/imagem na produção musical eletroacústica de compositores brasileiros atuantes no Rio de Janeiro: do gesto instrumental tradicional às interfaces interativas em tempo real. Doctoral dissertation, Rio de Janeiro, BR: Universidade Federal do Estado do Rio de Janeiro.

Lima, Marcelo Carneiro de. 2011. Vídeo-Música. Doctoral dissertation, Rio de Janeiro, BR: Universidade Federal do Estado do Rio de Janeiro.

Menezes, Flo. 1996. Música Eletroacústica: História e estéticas. São Paulo: Fundação Editora da UNESP.

Menezes, Flo. 1998. Atualidade estética da música eletroacústica. São Paulo: Fundação Editora da UNESP.

Murray, Christopher Brent. 2016. “Olivier Messiaen's Timbres-durées”. In.: Dingle, C. e Fallon, R. (ed.). Messiaen Perspectives 1: Sources and Influences. New York: Routledge.

Rekvelt, Joost. 2019. Light matters: the origin of the term visual music. http://www.joostrekveld.net/?p=1105.

Sanches, Alexandre Martinello. 2010. "Estruturação Audiovisual Através de Qualidades Morfológicas." Master dissertation, São Paulo, BR: Unicamp.

Santaella, Lucia. 2001. Matrizes da linguagem e pensamento: Sonora, Visual, Verbal. Aplicações na hipermídia. São Paulo: Iluminuras / Fapesp.

Schulz, B. 1999. Silent Music. Ed. Robin Minard. Heidelberg: Kehrer Verlag.

Schaeffer, Pierre. 2010. Ensaio sobre o rádio e o cinema: estética e técnica das artes-relé 1941-1942. Trad.: Carlos Palombini. Belo Horizonte: Editora UFMG.

Tagg, 1982. "Analysing popular music: theory, method and practice". In.: Popular Music, 2: 37-65.

Vande Gorne, A. 2002. "L'interprétation spatiale". In.: Revue DEMéter-Revue Électronique, Université de Lille-3. http://demeter.revue.univ-lille3.fr/interpretation/vandegorne.pdf. 